\title{
Genetic association of growth traits with carcass and meat traits in Nellore cattle
}

\author{
R.L. Tonussi', R. Espigolan', D.G.M. Gordo', A.F.B. Magalhães ${ }^{1}$, \\ G.C. Venturini ${ }^{1}$, F. Baldi ${ }^{1}$, H.N. de Oliveira ${ }^{1}$, L.A.L. Chardulo ${ }^{2}$, H. Tonhati ${ }^{1}$ and \\ L.G. de Albuquerque ${ }^{1}$ \\ 'Departamento de Zootecnia, Faculdade de Ciências Agrárias e Veterinárias, \\ Jaboticabal, SP, Brasil \\ 2Departamento de Química, \\ Universidade Estadual Paulista Júlio de Mesquita Filho, Instituto de Biociências, \\ Botucatu, SP, Brasil
}

Corresponding author: L.G. de Albuquerque

E-mail: Igalb@fcav.unesp.br

Genet. Mol. Res. 14 (4): 18713-18719 (2015)

Received August 22, 2015

Accepted October 29, 2015

Published December 28, 2015

DOI http://dx.doi.org/10.4238/2015.December.28.20

ABSTRACT. The aim of this study was to estimate genetic and phenotypic associations of growth traits with carcass and meat traits in Nellore cattle. Data from male and female animals were used for weaning weight (WW; N $=241,416)$, yearling weight $(\mathrm{YW}, \mathrm{N}=126,596)$, weight gain from weaning to yearling ( $G W Y, N=78,687$ ), and yearling hip height ( $Y H H, N=90,720$ ), respectively; 877 male animals were used for hot carcass weight (HCW) and 884 for longissimus muscle area (LMA), backfat thickness (BT), marbling score (MS), and shear force (SF). The variance components were estimated by the restricted maximum likelihood method using three-trait animal models that included WW. The model for WW included direct and maternal additive genetic, maternal permanent environmental, and residual effects as random effects; contemporary group as fixed effects; and age of dam at calving and age of animal as covariates (linear and quadratic effects). For the other traits, maternal effects and the effect of age of dam at calving were excluded from the model. Heritability ranged from $0.10 \pm$ 
0.12 (LMA) to $0.44 \pm 0.007$ (YW). Genetic correlations ranged from $-0.40 \pm$ 0.38 (WW $x$ LMA) to $0.55 \pm 0.10$ (HCW x YW). Growth, carcass, and meat traits have sufficient genetic variability to be included as selection criteria in animal breeding programs.

Key words: Genetic correlation; Longissimus muscle area; Shear force; Zebu

\section{INTRODUCTION}

Brazil occupies an important place in world food production, particularly that of beef. Traits associated with the quality of the product, such as carcass and meat traits, have gained significance for the determination of the price of meat and for access to new markets.

Carcass traits such as weight, longissimus muscle area (LMA), and subcutaneous fat thickness are important for the commercialization of meat products, since they are indicators of the quantitative and qualitative composition of meat (Luchiari Filho, 2000). This study also showed that LMA is related to muscling and yield of the edible portion, while subcutaneous fat thickness is used as an indicator of the degree of carcass finishing. With respect to meat traits, marbling favors mastication and adds flavor, and it serves as an indicator of intramuscular fat (Thompson, 2004). On the other hand, tenderness is an important trait for the acceptance of meat by consumers (Boleman et al., 1997).

All breeding programs of Zebu beef cattle breeds use growth traits such as weight and/ or weight gain at different ages as the selection criteria. However, selection based on carcass and meat traits, assessed post-mortem, is difficult and costly, and is therefore, still limited. Knowledge of the genetic association between growth and carcass and meat traits would, therefore, not only indicate the effect of selection for growth on these traits, but it would also allow identification of possible indicators for the selection of these traits.

The aim of the present study was to estimate genetic and phenotypic association of growth traits with carcass and meat traits in Nellore cattle to generate data for the genetic improvement of these traits.

\section{MATERIAL AND METHODS}

Data from Nellore cattle belonging to eight farms located in different regions of Brazil, which participate in the DeltaGen, Paint-CRV Lagoa, and Nelore Qualitas breeding programs, were used. The animals were reared on pasture and only kept in feedlots during the finishing phase for a period of 90 days. The animals were slaughtered at a mean age of $704 \pm 52$ days. Data from 241,416, 126,596, 78,687, and 90,720 male and female animals born between 2000 and 2011 were used for weaning weight (WW), yearling weight (YW), weight gain from weaning to yearling (GWY), and yearling hip height $(\mathrm{YHH})$, respectively. For carcass and meat traits, 884 male animals born between 2008 and 2010 to 117 bulls (7.5 progeny per bull) were used. Records of LMA, backfat thickness (BF), marbling score (MS), and shear force (SF) were available for all the animals whereas those for hot carcass weight (HCW) were available for 877 animals. The animals were weaned at a mean age of $205 \pm 31$ days and weighed at yearling, at $506 \pm 46$ days of age.

The carcass and meat traits were obtained after the slaughters that occurred at commercial slaughterhouses in different regions of the country. Immediately after slaughter, the carcasses 
were divided into half, identified, and cooled for at least $48 \mathrm{~h}$ post mortem. Thereafter, the halfcarcasses were deboned and longissimus dorsi muscle samples were obtained. The samples were frozen and transported to the Laboratory of Meat Quality Control and Certification (Laboratório de Qualidade e Certificação da Carne - LQCC) in Pardinho, São Paulo, where they were analyzed.

For the measurement of carcass and meat traits, the samples were cut into one-inch $(2.54 \mathrm{~cm})$ pieces between the $12^{\text {th }}$ and $13^{\text {th }}$ ribs across the longissimus dorsi muscle. LMA was measured using a method points quadrants (where each square corresponds to $1 \mathrm{~cm}^{2}$ ), which was placed over the sample. The sum of all squares corresponded to the LMA of the animal. A caliper was used for the determination of subcutaneous fat thickness. The layer of subcutaneous fat (measured in millimeters) located at an angle of $45^{\circ}$ from the geometric center was measured. The measurements of marbling were made according to the method described by Bertelsen (1997).

The procedure proposed and standardized by Wheeler et al. (1995) was used for the analysis of SF (without maturation of the meat). The samples were thawed until they reached a temperature of $2^{\circ}-5^{\circ} \mathrm{C}$, identified, and baked until the internal temperature reached $71^{\circ} \mathrm{C}$. The internal temperature was controlled with a thermocouple connected to a thermometer. The samples were then cooled at room temperature and stored in a refrigerator for $12-24 \mathrm{~h}$. Thereafter, $6-8$ meat cylinders (each one with a diameter of $1 / 2$ inch) were removed from the center of the sample longitudinal to the muscle fibers by using a manual dielectric device. Tenderness was determined using a mechanical Warner-Bratzler Shear Force equipment with a capacity of $25 \mathrm{~kg}$ and sectioning speed of $20 \mathrm{~cm} / \mathrm{min}$. The tenderness value of each sample, expressed as kilograms $(\mathrm{kg})$, was the arithmetic mean of the cylinders tested as described above.

Analysis by the least square method was performed using the GLM procedure of the SAS 9.1 program (SAS Institute INC., 2002-2003, Cary, NC, USA) to define the contemporary groups (CGs). For WW, the CG comprised farm, year of birth, management group at weaning, and sex. For $Y W, G W Y$, and $Y H H$, the management group at yearling was added to the CG. For the carcass and meat traits, the CG was defined as described for the other traits at yearling, excluding the effect of sex. CGs with fewer than 3 animals were excluded from the analysis of meat and carcass traits and those with fewer than 10 animals were excluded from the analysis of growth traits. After confirmation of consistency of the phenotypic data, the mean values and standard deviations of each trait studied were as follows: $170.50 \pm 28.26 \mathrm{~kg}(\mathrm{WW}), 267.37 \pm 0.3 \mathrm{~kg}$ (YW), $0.28 \pm 0.06 \mathrm{~g} /$ day (GWY), $132.03 \pm 6.08 \mathrm{~cm}(\mathrm{YHH}), 270.08 \pm 20.27 \mathrm{~kg}(\mathrm{HCW}), 65.39 \pm 8.06 \mathrm{~cm}(\mathrm{LMA}), 6.29 \pm$ $3.09 \mathrm{~mm}(\mathrm{BF}), 3.06 \pm 0.43(\mathrm{MS})$, and $4.90 \pm 1.26 \mathrm{~kg}(\mathrm{SF})$.

Three-trait analysis using an animal model was performed to obtain the variance components necessary for genetic parameter estimation. WW was included in each analysis to minimize the effect of selection during this phase. For WW, the model included direct and maternal additive genetic, maternal permanent environmental, and residual effects as random effects; fixed effects of CG; and age of dam at calving (ADC) and age of animal as covariates (linear and quadratic effects). For the remaining traits, maternal effects (genetic and permanent environmental) and the effect of ADC were excluded. The model can be written in matrix representation as follows:

$$
\mathrm{y}=\mathrm{Xb}+\mathrm{Z}_{1} \mathrm{a}+\mathrm{Z}_{2} \mathrm{~m}+\mathrm{Z}_{3} \mathrm{c}+\mathrm{e}
$$

where, $y=$ matrix of observed traits; $b=$ matrix of fixed effects; $a=$ matrix of direct additive genetic effects; $m=$ matrix of maternal additive genetic effects; $c=$ vector of maternal permanent environmental effects; $e=$ vector of residual effects, and $X, Z_{1}, Z_{2}$, and $Z_{3}=$ incidence matrices relating $b, a, m$ and, $c$ to $y$. In this study, it was assumed that $\mathrm{E}[\mathrm{y}]=\mathrm{Xb} ; \operatorname{Var}(\mathrm{a})=\mathrm{A} \otimes \mathrm{S}_{\mathrm{a}} ; \operatorname{Var}(\mathrm{m})=\mathrm{A}$ 
$\otimes S_{m} ; \operatorname{Var}(c)=I \otimes S_{c}$, and $\operatorname{Var}(e)=I \otimes S_{e}$, where $S_{a}$ was the matrix of additive genetic covariances; $S_{\mathrm{m}}$ was the matrix of maternal genetic variance, $S_{\mathrm{c}}$ was the matrix of maternal permanent environmental variance; $S_{\mathrm{e}}$ was the matrix of residual covariance; $A$ was the numerator matrix of additive genetic relationships; I was the identity matrix, and $\otimes$ was the direct product between the matrices. It was also assumed that $a, m, c$, and $e$ were not correlated. (Co) variance components and genetic parameters were estimated by the restricted maximum likelihood method using the Wombat program (Meyer, 2007). The relationship matrix included data of 289,545 animals (242,080 animals with phenotypic data; 1,172 sires; 84,068 cows; and 860 maternal grandparents). The mean inbreeding coefficient of the population was $0.04 \%$.

\section{RESULTS AND DISCUSSION}

The heritability estimates (Table 1) for the growth traits (WW, YW, GWY, and YHH) ranged from $0.12 \pm 0.009$ to $0.44 \pm 0.007$. These estimates are similar to those reported in the literature for the same traits in Nellore animals (Laureano et al., 2011; Boligon and de Albuquerque, 2012; Ferriani et al., 2013). All traits should, therefore, respond rapidly to direct selection, except for GWY, which exhibited a heritability of 0.12 .

Table 1. Estimates of the components of additive genetic $\left(\sigma^{2}\right)$, maternal additive genetic $\left(\sigma^{2}\right)$, maternal permanent environmental $\left(\sigma_{\mathrm{em}}^{2}\right)$, residual $\left(\sigma_{\mathrm{e}}^{2}\right)$, and phenotypic variance $\left(\sigma_{\mathrm{p}}^{2}\right)$ and heritability $\left(\mathrm{h}^{2}\right)$, and the corresponding standard error (SE) for growth, carcass, and meat traits in Nellore cattle.

\begin{tabular}{|c|c|c|c|c|c|c|c|}
\hline Trait & $\sigma_{a}^{2}$ & $\sigma_{\mathrm{m}}^{2}$ & $\sigma_{\mathrm{em}}^{2}$ & $\sigma_{\mathrm{e}}^{2}$ & $\sigma_{\mathrm{p}}^{2}$ & $h^{2}$ & SE \\
\hline$\overline{W W}$ & 97.40 & 18.97 & 51.94 & 158.75 & 327.06 & 0.30 & 0.008 \\
\hline YW & 249.37 & - & - & 322.10 & 571.47 & 0.44 & 0.007 \\
\hline GWY & $0.2069^{*}$ & - & - & $1.4677^{*}$ & $1.6746^{*}$ & 0.12 & 0.009 \\
\hline $\mathrm{YHH}$ & 4.84 & - & - & 7.63 & 12.47 & 0.38 & 0.009 \\
\hline $\mathrm{HCW}$ & 90.04 & - & - & 138.46 & 228.50 & 0.39 & 0.15 \\
\hline LMA & 5.64 & - & - & 50.93 & 56.57 & 0.10 & 0.12 \\
\hline $\mathrm{BF}$ & 0.76 & - & - & 3.79 & 4.55 & 0.17 & 0.14 \\
\hline MS & 0.039 & - & - & 0.102 & 0.141 & 0.28 & 0.18 \\
\hline SF & 0.24 & - & - & 0.89 & 1.13 & 0.21 & 0.16 \\
\hline
\end{tabular}

*Values multiplied by $1000 . W W=$ weaning weight, $Y W=$ yearling weight, $G W Y=$ weight gain from weaning to yearling, $\mathrm{YHH}=$ yearling hip height, $\mathrm{HCW}=$ hot carcass weight, $\mathrm{LMA}=$ longissimus muscle area, $\mathrm{BF}=$ backfat thickness, $\mathrm{MS}=$ marbling score, $\mathrm{SF}=$ shear force.

The heritabilities of the carcass traits were of low magnitude for LMA $(0.10)$ and $B F(0.17)$ and of high magnitude for HCW (0.39; Table 1). Riley et al. (2002) reported a similar heritability for HCW (0.44). The heritabilities found in the literature for the other carcass traits studied ranged from 0.44 to 0.50 for LMA and from 0.36 to 0.63 for BF in Zebu animals (Riley et al., 2002; Smith et al., 2007).

With respect to meat traits, Riley et al. (2002) and Smith et al. (2007) reported heritabilities of 0.37 and 0.44 , respectively, for marbling in Bos indicus animals. For SF, the heritabilities obtained by those authors agree with those observed in the present study. It should be noted that these meat traits cannot be measured directly in the animal to be selected and are, therefore, not subject to direct selection. However, these results permit the conclusion that in adequately designed progeny tests, a number of 10 to 20 progenies per sire would be necessary to obtain a reasonable accuracy.

The genetic correlations of HCW with WW, YW, and YHH were moderate and positive, while the correlation with GWY was practically zero (Table 2). The latter result differs from that obtained for Brahman cattle (0.84) by Riley et al. (2002). Ferriani et al. (2013), using a smaller number of observations in Nellore cattle, estimated a moderate genetic correlation of $0.69 \pm 0.16$ 
between HCW and WW. These authors also reported a lower genetic correlation between HCW and $\mathrm{YHH}(0.09 \pm 0.21)$ compared to that obtained in the present study. The remaining genetic correlations with $\mathrm{HCW}$ were of moderate magnitude, indicating a favorable action between the gene effects to these traits. Hence, selection for weights at different ages results in a favorable correlated response in the same direction for HCW.

\begin{tabular}{|c|c|c|c|c|c|}
\hline & $\mathrm{HCW}$ & LMA & BF & MS & SF \\
\hline WW & $0.48 \pm 0.23$ & $-0.40 \pm 0.38$ & $-0.20 \pm 0.24$ & $-0.01 \pm 0.20$ & $0.14 \pm 0.23$ \\
\hline YW & $0.55 \pm 0.10$ & $-0.15 \pm 0.30$ & $-0.25 \pm 0.22$ & $0.03 \pm 0.20$ & $0.20 \pm 0.23$ \\
\hline GWY & $-0.07 \pm 0.49$ & $-0.06 \pm 0.37$ & $0.40 \pm 0.40$ & $0.24 \pm 0.26$ & $0.20 \pm 0.29$ \\
\hline YHH & $0.45 \pm 0.12$ & $-0.37 \pm 0.37$ & $-0.39 \pm 0.22$ & $0.23 \pm 0.20$ & $0.25 \pm 0.21$ \\
\hline
\end{tabular}

$\mathrm{WW}=$ weaning weight, $\mathrm{YW}=$ yearling weight, $\mathrm{GWY}=$ weight gain from weaning to yearling, $\mathrm{YHH}=$ yearling hip height, $\mathrm{HCW}=$ hot carcass weight, $\mathrm{LMA}=$ longissimus muscle area, $\mathrm{BF}=$ backfat thickness, $\mathrm{MS}=$ marbling score, $\mathrm{SF}=$ shear force (tenderness).

The genetic correlations between the other carcass traits (LMA and BF) and growth traits were negative but low, except for the correlations of WW and $\mathrm{YHH}$ with LMA and of GWY and YHH with BF. Thus, selection for increasing YW should not affect carcass traits such as LMA and BF. With respect to the genetic correlation between WW and LMA, this result was not expected since the latter trait is an indicator of the proportion of edible meat in the carcass. Low genetic correlation estimates between growth and carcass traits were also reported by other authors such as: Splan et al. (2002), 0.29 and -0.28 of WW with LMA and BF, and Wheeler et al. (2005), 0.18 and 0.14 of YW with LMA and BF, respectively.

The genetic correlation between LMA and GWY was practically zero (0.06; Table 2), indicating that selection for one trait should not affect the other. This result disagrees with the estimates obtained by Riley et al. (2002) for Brahman cattle, who observed a moderate genetic correlation between LMA and GWY (0.49). In contrast, the genetic correlation between BF and GWY was moderate and positive $(0.40)$ and was similar to that reported $(0.58)$ by Riley et al. (2002), indicating that selection of animals with higher GWY may be a suitable alternative to improve subcutaneous fat deposition in the carcass.

The genetic correlations between the carcass traits (LMA and BF) and $\mathrm{YHH}$ were moderate and negative (-0.37 and -0.39 , respectively; Table 2$)$, i.e., selection for greater height of the animals will reduce LMA and BF. Studying Brahman cattle, Riley et al. (2002) reported a lower genetic correlation between LMA and $\mathrm{YHH}(-0.12)$ and a similar correlation between BF and YHH (-0.32). Thus, long-term selection for an increase in animal height should lead to animals that deposit less fat due to a correlated response.

The genetic correlations between MS and weights (WW and YW) were practically zero (Table 2), indicating that the use of these weights as selection criteria will not lead to genetic changes in marbling. Splan et al. (2002) found a genetic correlation of 0.28 between MS and WW, a value slightly higher than that obtained in the present study. Wheeler et al. (2005), studying taurine animals, also obtained a low genetic correlation (0.10) between MS and YW. However, in the present study, the genetic correlations of MS with GWY and YHH were low and positive (Table 2). Similar genetic correlations between MS and GWY have been reported by Riley et al. (2002) and Smith et al. (2007) for Brahman cattle, with correlations of 0.28 and 0.27 , respectively. However, Riley et al. (2002) obtained a genetic correlation of -0.27 between MS and YHH.

Low positive genetic correlations were observed between SF and the growth traits (Table 
2). Therefore, long-term selection for an increase in weight or weight gain may cause an undesirable change in meat tenderness. The latter is one of the most important traits of meat quality and is fundamental to cope with the increasing demands of consumer markets; however, producers are not paid by meat tenderness. The present result indicates that the selection performed with emphasis on weights and/or weight gains may lead to the production of less tender meat. Splan et al. (2002) reported a lower genetic correlation, almost zero (0.05), between growth traits and meat tenderness, while Wheeler et al. (2005) obtained a higher estimate (0.55).

The phenotypic correlations between growth traits (WW, YW, and $\mathrm{YHH}$ ) and $\mathrm{HCW}$ were positive (Table 3), indicating that taller and heavier animals have a higher carcass weight. However, the phenotypic correlations between the growth and meat traits (Table 3) were close to zero, i.e., the growth traits are not good indicators of traits associated with meat quality.

Studies reporting genetic parameter estimates for traits measured after slaughter are sparse in the literature, and even fewer studies have evaluated the genetic correlations of growth traits with carcass and meat traits in Zebu cattle. Most studies investigating these traits were conducted on animals of Bos taurus origin and their crosses (Burrow et al., 2001). Furthermore, many of these studies involved animals from experimental herds, while in the present study carcass and meat data of commercial herds were used.

\begin{tabular}{|c|c|c|c|c|c|}
\hline & $\mathrm{HCW}$ & LMA & $\mathrm{BF}$ & MS & SF \\
\hline WW & $0.48 \pm 0.03$ & $0.11 \pm 0.05$ & $0.03 \pm 0.04$ & $0.01 \pm 0.05$ & $0.04 \pm 0.05$ \\
\hline YW & $0.72 \pm 0.017$ & $0.13 \pm 0.05$ & $0.02 \pm 0.04$ & $0.01 \pm 0.05$ & $0.03 \pm 0.05$ \\
\hline GWY & $0.08 \pm 0.09$ & $-0.07 \pm 0.07$ & $0.06 \pm 0.07$ & $-0.07 \pm 0.07$ & $-0.14 \pm 0.07$ \\
\hline YHH & $0.49 \pm 0.03$ & $-0.02 \pm 0.05$ & $0.06 \pm 0.04$ & $0.05 \pm 0.04$ & $0.04 \pm 0.05$ \\
\hline
\end{tabular}

$W W=$ weaning weight, $Y W=$ yearling weight, $G W Y=$ weight gain from weaning to yearling, $Y H H=$ yearling hip height, $\mathrm{HCW}=$ hot carcass weight, LMA = longissimus muscle area, BF = backfat thickness, $\mathrm{MS}=$ marbling score, $\mathrm{SF}=$ shear force (tenderness).

In view of the difficulty and cost implications of measuring these traits encountered by most studies, including the present one, a relatively small number of data are available for the estimation of genetic parameters. The results of genetic parameter estimates described in the literature are conflicting owing to differences in the environment, breed, population structure, and sample size. The genetic correlations obtained should, therefore, be viewed with caution since the standard errors of these correlations were relatively high. Further studies considering these meat and carcass traits measured post mortem need to be conducted. The availability of a larger number genetic parameter estimates obtained from Zebu data under tropical conditions will permit the design of breeding programs to improve carcass and meat quality.

\section{CONCLUSIONS}

Growth, carcass, and meat traits exhibit sufficient genetic variability to be considered as selection criteria in animal breeding programs. Long-term selection for growth traits such as WW, $\mathrm{YW}$, and $\mathrm{YHH}$ may promote desirable changes in HCW. However, selection for these traits could reduce meat tenderness and, therefore, affect the quality of the product. However, selection for GWY will not affect LMA and may be a suitable alternative to improve the degree of carcass finishing. Therefore, indicator traits of carcass and meat quality should be included as criteria in the selection index to improve these traits. 


\section{Conflicts of interest}

The authors declare no conflict of interest.

\section{ACKNOWLEDGMENTS}

The authors would like to thank Fundação de Amparo do Estado de São Paulo (FAPESP) for funding this study (Grant \#2009/16118-5 and \#2012/21969-7).

\section{REFERENCES}

Bertelsen B (1997). U.S. premium beef. USDA quality grades and yield grades. http://www.uspremiumbeef.com/Documentltem. aspx?ID=21. Accessed September 23, 2015.

Boleman SJ, Boleman SL, Miller RK, Taylor JF, et al. (1997). Consumer evaluation of beef of known categories of tenderness. J. Anim. Sci. 75: 1521-1524.

Boligon AA and de Albuquerque LG (2012). Genetic parameters and relationships between heifers rebreeding and hip height in Nellore cattle. R. Bras. Zootec. 41: 598-602.

Burrow HM, Moore SS, Johnston DJ, Barendse W, et al. (2001). Quantitative and molecular genetic influences on properties of beef: a review. Aust. J. Exp. Agric. 41: 893-919.

Ferriani L, Albuquerque LG, Baldi FSB, Venturini GC, et al. (2013). Parâmetros genéticos de características de carcaça e de crescimento de bovinos da raça Nelore. Arch. Zootec. 62: 123-129.

Laureano MMM, Boligon AA, Costa RB, Forni S, et al. (2011). Estimativas de herdabilidade e tendências genéticas para características de crescimento e reprodutivas em bovinos da raça Nelore. Arq. Bras. Med. Vet. Zootec. 63: $143-152$.

Luchiari Filho A (2000). Pecuária da carne bovina. 1edn. LinBife, São Paulo.

Meyer K (2007). WOMBAT - A tool for mixed model analyses in quantitative genetics by restricted maximum likelihood (REML). J. Zhejiang Univ. Sci. B. 8: 815-821.

Riley DG, Chase CC Jr, Hammond AC, West RL, et al. (2002). Estimated genetic parameters for carcass traits of Brahman cattle. J. Anim. Sci. 80: 955-962.

SAS Institute INC (2002-2003). Statistical analysis system. Release 9.1. (Software). Cary. USA.

Smith T, Domingue JD, Paschal JC, Franke DE, et al. (2007). Genetic parameters for growth and carcass traits of Brahman steers. J. Anim. Sci. 85: 1377-1384.

Splan RK, Cundiff LV, Dikeman ME and Van Vleck LD (2002). Estimates of parameters between direct and maternal genetic effects for weaning weight and direct genetic effects for carcass traits in crossbred cattle. J. Anim. Sci. 80: 3107-3111.

Thompson JM (2004). The effects of marbling on flavour and juiciness scores of cooked beef, after adjusting to a constant tenderness. Aust. J. Exp. Agric. 44: 645-652.

Wheeler TL, Koohmaraie M and Shackelford SD (1995). Standardized Warner-Bratzler shear force procedures for meat tenderness measurement. Clay Center: Roman L. Hruska U. S. Meat Animal Research Center. United States Department of Agriculture.

Wheeler TL, Cundiff LV, Shackelford SD and Koohmaraie M (2005). Characterization of biological types of cattle (Cycle VII): Carcass, yield, and longissimus palatability traits. J. Anim. Sci. 83: 196-207. 